\title{
NOTA AL EDITOR
}

\section{Pedro L. Sotolongo* (En Homenaje póstumo a ÁLVARO MÂRQUEZ FERNÁNDEZ).}

Corría un año de comienzos de este Siglo, -si mal no recuerdo era por el 2006 o 2007 (hoy en día, con el frenético ritmo de la vida cotidiana, esa fecha se nos aparece ya como una ocasión lejana) cuando visité Venezuela una vez más - esta vez Maracaibo, en el Estado Zulia- por gentil invitación de Álvaro Márquez, con quién había entablado relación el año anterior (de nuevo, si la memoria no me falla) por asuntos editoriales.

En aquella ocasión, Álvaro tuvo la gentileza de organizar, junto a colegas suyos, para mi estancia en sus predios, una suerte de Seminario denominado: $E l$ Pensamiento -y las Ciencias- de la Complejidad: Las estrategias de indagación de fenómenos complejos, campo emergente (desde el último tercio del recién finalizado Siglo) del Saber contemporáneo en el que desenvuelvo mi labor desde el año 2000 (entre otras actividades, en aquel entonces, como Presidente de la Cátedra de Complejidad de La Habana, creada por mí).

Durante dicha estancia, todo el tiempo, conté con la atención personal de Álvaro, quien se afanó porque yo pudiera conocer lo más posible de aquellos lares. Recuerdo aún nuestra excursión juntos al lago Maracaibo, su explicación de los avatares del nivel de las aguas en ese lugar, las complicaciones de la producción y refinación del petróleo allí, etc. Más de una vez disfruté de comidas junto a Álvaro, tanto en lugares conocidos como en otros más recoletos.

\footnotetext{
*Unión Nacional de Escritores de Cuba (UNEAC). Cuba. Correo electrónico pedro.sotolongo@ yahoo.com 285
} 
Tengo en la memoria aquel Seminario, que comenzó con unas palabras de la Profesora Mag. Judith Rodríguez, entonces Directora del Centro de Estudios Sociológicos y Antropológicos (CESA), seguida de una Conferencia Inaugural a mi cargo denominada "Los retos de las Ciencias de la Complejidad para el Pensamiento Social contemporáneo”. Acto seguido tuvo lugar una generosa Presentación -a cargo precisamente de Álvaro Márquez- de colaboraciones editoriales nuestras con él, recientes en aquel momento; así como del libro nuestro Teoría Social y Vida Cotidiana: La Sociedad como Sistema Dinámico Complejo, a la sazón de reciente publicación en La Habana por Editorial Acuario (y posteriormente, vuelto a imprimir, esta vez en Santo Domingo, Rep. Dominicana).

Todo ello ocurrió en el Auditorium de Postgrado de la Facultad de Ciencias Económicas y Sociales y se extendió de martes a sábado. ¡Gracias, una vez más, Álvaro por tu solidaridad profesional!

Fue aquello propicia ocasión también para para sostener entrevistas nuestras, en PRENSA-LUZ y LUZ-FM, así como para reunirme con los investigadores del ya aludido CESA y de presentaciones de programas de TV. También propició Álvaro una visita nuestra a la Universidad Católica 'Cecilio Acosta' (UNICA), donde llevé a cabo, en su Sala de Conferencias, una acerca del Pensamiento y Ciencias de la Complejidad: Un Saber acerca 'de-lo-que-quedó-en-el-medio'. También tuve ocasión de reunirme con colegas -soy Doctor (Ph.D.) en Filosofía- profesores e investigadores de la Facultad de Filosofía y de la Maestría en Filosofía de la Universidad de Zulia...

Finalizada esa actividad, gozamos de la compañía de Álvaro en actividades colaterales y partimos rumbo a Caracas, con escala en Valencia.

No fue esa ni la primera, ni la última ocasión en que Álvaro y yo colaboráramos. Incluso en fecha muy reciente, estando Álvaro colaborando en la vecina a su país Colombia, tuvimos ocasión de varias iniciativas editoriales conjuntas -siempre vinculadas a ese campo del Saber: el Pensamiento y Ciencias de la Complejidad. E 
Pedro L. Sotolongo

Telos Vol. 21, No. 2 (2019). 285-287

incluso la infeliz noticia de su fallecimiento me sorprendió atareado en cumplir otra de tales colaboraciones.

¡Descanse en paz, Álvaro Márquez Fernández! Tu recuerdo y la generosidad de tu persona me acompañarán siempre... 